\title{
IMPORTÂNCIA DA FISIOTERAPIA NA PREVENÇÃO DE DISTÚRBIOS OSTEOMUSCULARES RELACIONADOS AO TRABALHO
}

Luciana Hippler Zandonadi, Thayná Araujo Maiolini Costa, Priscila Figueiredo Correia, Deborah Cristina Gonçalves Luiz Fernani, Maria Tereza Artero Prado Dantas

Universidade do Oeste Paulista - UNOESTE, Curso de Fisioterapia, Presidente Prudente, SP. E-mail: mariatereza@unoeste.br

\section{RESUMO}

Os objetivos deste estudo foram analisar como os estudos apresentaram a atuação da fisioterapia como prevenção de distúrbios osteomusculares relacionados ao trabalho (DORT) e enfatizar a sua importância. Tratou-se de um estudo de revisão de literatura, com artigos publicados no período de janeiro de 1998 a outubro de 2017. Foram analisados seis artigos, todos utilizaram questionários para avaliação da dor e/ou qualidade de vida do trabalhador, dois estudos utilizaram o check-list e fotos para análise do ambiente de trabalho e um estudo utilizou filmagens para avaliação ergonômica. Foram feitas análises e modificações ergonômicas, orientações posturais e de atividade física e a realização de ginástica laboral em parte dos estudos. Portanto, os estudos apresentaram resultados positivos em relação a medidas preventivas aos DORT, além de relatarem a consequente melhoria da qualidade de vida dos trabalhadores, o que reflete no aumento da produtividade, fato que enfatiza a importância da aplicação da fisioterapia preventiva.

Palavras-chave: qualidade de vida, trabalhadores, fisioterapia, prevenção primária, transtornos traumáticos cumulativos.

\section{IMPORTANCE OF PHYSIOTHERAPY IN PREVENTING WORK-RELATED SKELETAL MUSCLE DISORDERS}

\begin{abstract}
The aims of this study were to analyze as the studies showed the acting of physiotherapy as prevention of work-related musculoskeletal Disorders (WMSDs) and to emphasize your importance. It was a bibliographic review, with articles published from January 1998 to October 2017. And, it was analyzed six articles, all studies used questionnaires to assess pain and/or worker's quality of life, two studies used the check-list and photos for analyze the environment and one study used filming for ergonomic evaluation. Analysis and ergonomic modifications were made, postural and physical activity guidance, and to performing labor gymnastics in part of the studies. Therefore, the studies showed positive results in relation to preventive measures to WMSDs, in addition to reporting the consequent improvement of the quality of life of workers, reflecting the increase in productivity, fact that emphasizes the importance of applying preventive physiotherapy.
\end{abstract}

Keywords: quality of life, workers, physical therapy specialty, primary prevention, cumulative trauma disorders.

\section{INTRODUÇÃO}

Os Distúrbios Osteomusculares Relacionados ao Trabalho (DORT), também podem ser denominados como transtornos traumáticos cumulativos, que são um conjunto de doenças que afetam tendões, músculos, nervos e vasos do corpo, principalmente dos membros superiores e inferiores, que apresentam relação direta com a exigência da tarefa, ambiente e organização de trabalho ${ }^{1}$, decorrente da exigência do uso excessivo do sistema musculoesquelético, junto à falta de tempo para recuperação do mesmo ${ }^{2}$. 
Vinculado a estes acometimentos, vários são os sintomas dos trabalhadores como: dor localizada, irradiada ou generalizada, formigamento, dormência, sensação de diminuição de força, enrijecimento muscular e falta de firmeza nas mãos. Nos casos mais crônicos e graves, podem ocorrer outros sintomas como, sudorese excessiva nas mãos e alodínea (sensação de dor a estímulos não nocivos na pele) ${ }^{3}$.

No mundo, ocorre cada vez mais o aumento do número de sintomas musculoesqueléticos advindos da DORT ${ }^{4}$, sendo considerados como problema de saúde pública, pois são responsáveis por quase $90 \%$ dos afastamentos do trabalho ${ }^{5}$ e em grande porcentagem, causam incapacidades, que muitas vezes são permanentes ${ }^{6}$.

Segundo o Ministério da Saúde ${ }^{2}$ a alta prevalência da DORT é devido a transformações do trabalho, das empresas e de suas necessidades, que visam meta de produção, lucros e competitividade, fato às vezes que não abrangem os limites físicos e psicossociais dos trabalhadores.

Depois de adquirida, a DORT causa muitos transtornos no decorrer da vida do trabalhador, sendo estes físicos e psicossociais, como a depressão, algias constantes, absenteísmo, aposentadoria por invalidez, o desenvolvimento de doenças predispostas geneticamente e podem trazer muitos prejuízos na qualidade de vida do indivíduo ${ }^{7}$. A qualidade de vida em muitos conceitos é sinônimo de saúde, felicidade e satisfação pessoal, condições de vida, estilo de vida, entre outros, sendo definida de acordo com o perfil do indivíduo ${ }^{8}$.

Dentre as estratégias em busca da qualidade de vida, prevenção, melhora e manutenção da saúde do trabalhador, sabe-se que a fisioterapia atua para diminuição dos fatores de riscos no local do trabalho e na prevenção do desenvolvimento das doenças ocupacionais ${ }^{9}$. Devido ao conhecimento dos altos índices de DORT no Brasil e no mundo, das incapacidades causadas por estes e dos benefícios da fisioterapia preventiva sobre estes acometimentos, justifica-se a realização deste estudo para apresentar e enfatizar a importância da implantação de programas que realizem prevenção de doenças ocupacionais na saúde pública.
Deste modo, esta pesquisa apresenta como objetivo realizar uma revisão de estudos que apresentam a atuação da fisioterapia para prevenção de distúrbios osteomusculares relacionados ao trabalho e enfatizar a sua importância.

\section{METODOLOGIA}

Esta pesquisa trata-se de uma revisão de literatura, na qual foram buscados artigos científicos no período de novembro de 2017, utilizando as seguintes bases de dados: Pubmed e Biblioteca Virtual em Saúde (BVS), que realiza pesquisa em diversas bases de dados como o Lilacs, Medline, Scielo e Biblioteca Cochrane. Foram coletados artigos que abrangem a temática e que foram publicados no período de janeiro de 1998 a outubro de 2017. Foram utilizados os seguintes descritores: trabalhadores, fisioterapia, prevenção, qualidade de vida, transtornos traumáticos cumulativos e seus correlatos na língua inglesa: workers, physicaltherapy, prevention, quality of life e cumulative trauma disordes, sendo realizadas combinações destas para as buscas.

Os critérios de inclusão para seleção dos artigos para este estudo foram: artigos clínicos, revisão de literatura e sistemática, que relatam e discutem sobre a realização de fisioterapia para prevenção de distúrbios osteomusculares relacionados ao trabalho. Foram excluídos os estudos que relataram ponto de vista e opinião de especialistas.

Inicialmente, foram selecionados os estudos com base nos títulos, para excluir os que não abordassem o respectivo tema. Depois, os resumos foram lidos para verificar se atendiam aos critérios de inclusão do estudo. Assim, os artigos que abordavam a temática e seguiam os critérios de inclusão, foram lidos por dois avaliadores e analisados independentemente. Em caso de discordância era encaminhado para um terceiro avaliador e discutido.

Para avaliação da qualidade dos estudos selecionados foi realizada uma avaliação independente pelos autores, nos quais os critérios utilizados eram estar em revistas indexadas e apresentar os dados necessários para análise. A extração dos dados dos artigos foi feita pela identificação dos objetivos do estudo, metodologia realizada, principais achados e 
conclusão. Assim foi formulado um quadro para melhor visualização e discussão das pesquisas.

\section{RESULTADOS}

A quantidade de artigos encontrados e selecionados em cada base de dados estão apresentados no fluxograma abaixo (Figura 1). Fizeram parte desta revisão seis artigos científicos de pesquisa experimentais, sendo um estudo controlado randomizado.

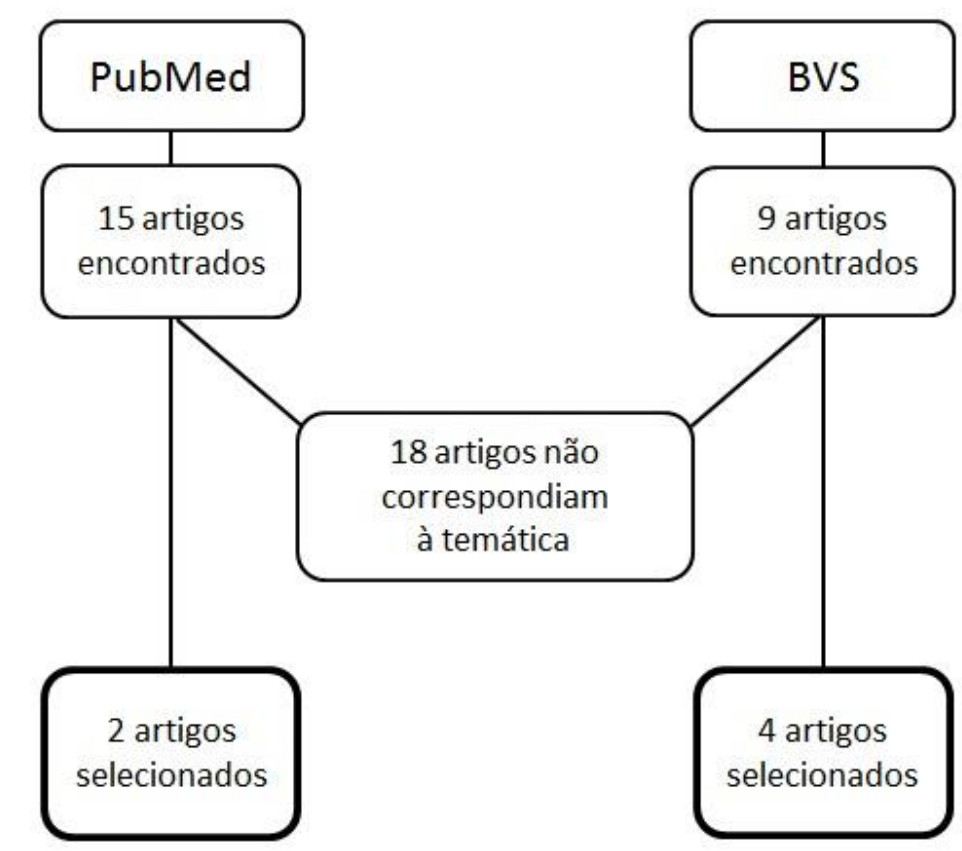

Figura 1. Fluxograma de caracterização dos artigos encontrados e selecionados nas bases de dados.

No Quadro 1 apresentam-se os principais conteúdos referentes aos objetivos, metologia, principais achados e conclusão dos seis estudos pesquisados e analisados. Em geral, foi observado nesta revisão que a aplicação da fisioterapia foi encontrada principalmente na forma de avaliação e intervenção ergonômica, orientações e ginástica laboral.

Todos os estudos analisados utilizaram para avaliação dos indivíduos questionários, em geral estes buscavam informações sobre dor, estresse, tempo de trabalho, pausa e o tipo da tarefa. 0 estudo 1 e 6 também utilizaram checklist e fotos para analisar o risco ergonômico. Já a pesquisa 2 utilizou a filmagem como meio para obter informações sobre o local e a forma de trabalho.

Todos os estudos relataram queixas de dor pelos trabalhadores em diversas regiões do corpo, como na região cervical, nos ombros, na lombar, braços, pescoço, membros inferiores, coluna dorsal e cabeça, sendo que esta sequência foi disposta de acordo com o maior número de relatos pelas pesquisas.

Nos estudos analisados, alguns autores relataram de modo geral e de diferentes formas que o trabalho realizado de forma contínua (sem pausas), na mesma posição e com movimentos repetitivos pode desencadear algias, principalmente em coluna, membros superiores e inferiores.

Os estudos 1, 2 e 6 também analisaram os postos de trabalho e realizaram intervenções ergonômicas, pois havia presença de irregularidade no mobiliário (estudo 2), ou mobiliários corretos, porém utilizados inadequadamente pelos indivíduos (6), ou parcialmente correto, mas com a disposição dos móveis no ambiente inadequada (1).

Em relação à prevenção, $50 \%$ dos estudos $(1,2$ e 3$)$ sugeriram outras medidas preventivas durante a pesquisa ou no seu término, por meio de panfletos e palestras informativas relacionadas à ergonomia, orientação postural e atividade física. 
Já $66,6 \%$ dos estudos (1, 2, 3 e 4) abordaram a ginástica laboral, na qual avaliaram a sua eficiência sobre o efeito da DORT, estresse laboral, relacionamento interpessoal e qualidade de vida. Estes estudos relataram que a ginástica laboral auxiliou de forma preventiva e curativa diretamente na DORT, além de melhorar a qualidade de vida do trabalhador. E para obtenção destas informações a respeito da evolução na QV, estes estudos aplicaram questionários que abordam esta temática antes e após a realização da ginástica laboral.

Quadro 1. Descrição dos estudos encontrados e analisados nesta pesquisa.

\begin{tabular}{|c|c|c|c|c|}
\hline Estudo & Objetivos & Metodologia & Principais resultados & Conclusão \\
\hline $\begin{array}{l}\text { Miyamoto } \\
\text { et al. }{ }^{10}\end{array}$ & $\begin{array}{l}\text { - Relacionar à } \\
\text { prevenção do } \\
\text { estresse } \\
\text { ocupacional } \\
\text { com a } \\
\text { abordagem } \\
\text { ergonômica do } \\
\text { posto a fim de } \\
\text { proporcionaliz } \\
\text { ar a } \\
\text { racionalização } \\
\text { e a } \\
\text { humanização } \\
\text { deste e de } \\
\text { obter } \\
\text { satisfação e } \\
\text { motivação } \\
\text { pessoal. }\end{array}$ & $\begin{array}{l}\text { - Amostra: } 110 \\
\text { funcionários ( } 78,1 \% \text { do } \\
\text { sexo feminino e } 21,9 \% \text { do } \\
\text { sexo masculino; idade } \\
\text { média de } 35 \text { anos). } \\
\text { - Foram aplicados } 3 \\
\text { questionários: sobre } \\
\text { estresse; dores físicas e } \\
\text { para analisar os } \\
\text { resultados do projeto de } \\
\text { conscientização, } \\
\text { orientação e atividade } \\
\text { física, que foi aplicado } \\
\text { aos trabalhadores. } \\
\text { - A observação do } \\
\text { ambiente geral e do } \\
\text { posto de trabalho foi feita } \\
\text { por meio de check-lists e } \\
\text { fotos. } \\
\text { - Foram utilizados } \\
\text { métodos } \\
\text { fisioterapêuticos } \\
\text { preventivos. Para a } \\
\text { realização foram } \\
\text { distribuídos } 13 \text { grupos de } \\
\text { cinco a oito pessoas, uma } \\
\text { vez por semana durante } \\
\text { três meses com } 15 \text { min } \\
\text { cada sessão. } \\
\text { - Durante o projeto foram } \\
\text { realizadas } 3 \text { palestras } \\
\text { para orientação. }\end{array}$ & $\begin{array}{l}\text { - 34,4\% dos funcionários } \\
\text { apresentaram estresse severo, } \\
29,7 \% \text { estresse moderado, } \\
29,7 \% \text { estresse leve e } 6,3 \% \text { sem } \\
\text { estresse. Os sintomas mais } \\
\text { frequentes seriam: músculos } \\
\text { tensos dor de cabeça, dores nas } \\
\text { costas, falta de entusiasmo e } \\
\text { cansaços constantes, } \\
\text { - 43,1\% relatam que a } \\
\text { sobrecarga no trabalho pode } \\
\text { influenciar no estresse. } \\
\text { - } 77 \% \text { dos funcionários relatam } \\
\text { dores e a maioria (67,8\%) já } \\
\text { tem a mais de um ano. } \\
\text { - 30,3\% já se afastaram do } \\
\text { trabalho em razão de algum } \\
\text { tipo de dor. } \\
\text { - O projeto de fisioterapia } \\
\text { preventiva implantado mesmo } \\
\text { em curto período, melhorou a } \\
\text { qualidade de vida de } 93,8 \% \text { dos } \\
\text { funcionários, } 98,5 \% \text { gostariam } \\
\text { da continuidade do projeto. } \\
\text { - Pelas fotos e o check-list, o } \\
\text { ambiente de trabalho parecia } \\
\text { ergonômico, porém verificaram } \\
\text { irregularidades. }\end{array}$ & $\begin{array}{l}\text { - A prevenção está } \\
\text { adquirindo lugar na vida } \\
\text { das pessoas e das } \\
\text { empresas. } \\
\text { - Simplesmente porque é } \\
\text { caro tratar da doença e da } \\
\text { incapacidade, além do que } \\
\text { os trabalhadores precisam } \\
\text { estar aptos e sadios para } \\
\text { enfrentar a alta } \\
\text { competitividade. }\end{array}$ \\
\hline $\begin{array}{l}\text { Ketola } \\
\text { et al. }{ }^{11}\end{array}$ & $\begin{array}{l}\text { - Avaliar o } \\
\text { efeito de uma } \\
\text { abordagem } \\
\text { ergonômica } \\
\text { intensiva e } \\
\text { educativa e os } \\
\text { distúrbios } \\
\text { musculoesquel } \\
\text { éticos entre os } \\
\text { trabalhadores } \\
\text { que utilizavam } \\
\text { monitores. }\end{array}$ & $\begin{array}{l}\text { - Amostra: funcionários } \\
\text { de três unidades } \\
\text { administrativas que } \\
\text { trabalhavam por mais de } \\
\text { quatro horas por semana } \\
\text { com monitor. } \\
\text { - } 515 \text { pessoas foram } \\
\text { convidadas a } \\
\text { responderem o } \\
\text { questionário sobre algias } \\
\text { musculoesqueléticas, } \\
\text { tensão, saúde em geral, } \\
\text { fatores do ambiente de }\end{array}$ & $\begin{array}{l}\text { - Ajustes foram realizados na } \\
\text { cadeira e na localização do } \\
\text { mouse. Apenas no grupo de } \\
\text { Ergonomia Intensiva foi } \\
\text { ajustada a altura da tela do } \\
\text { computador ou a aquisição de } \\
\text { acessórios } \\
\text { - No segundo mês de projeto o } \\
\text { grupo ergonomia intensiva } \\
\text { apresentou diminuição de dor } \\
\text { em pescoço, ombro, dedos do } \\
\text { que o grupo controle. } \\
\text { - O grupo ergonomia intensiva e }\end{array}$ & $\begin{array}{l}\text { - A abordagem } \\
\text { ergonômica intensiva e } \\
\text { educacional auxilia na } \\
\text { redução do desconforto } \\
\text { em trabalhadores que } \\
\text { utilizam monitores. }\end{array}$ \\
\hline
\end{tabular}




\begin{tabular}{|c|c|c|c|c|}
\hline & & $\begin{array}{l}\text { trabalho e tempo de } \\
\text { trabalho. Destes, } 124 \\
\text { apresentaram sintomas } \\
\text { musculoesqueléticos e } \\
\text { foram alocados em } 3 \\
\text { grupos porém no final } \\
\text { apenas } 107 \text { participaram } \\
\text { devido a mudança de } \\
\text { trabalho, recusa, licença } \\
\text { ou morte. } \\
\text { - Foram gravadas as } \\
\text { tarefas e a forma de } \\
\text { realizá-las no início, com } \\
\text { dois meses de } \\
\text { intervenção. } \\
\text { - Foi estabelecido um } \\
\text { questionário diário para } \\
\text { os participantes } \\
\text { responderem em } 3 \\
\text { períodos. } \\
\text { - Divisão dos Grupos: } \\
\text { Ergonomia intensiva: } \\
\text { avaliados por } \\
\text { fisioterapeutas e foi } \\
\text { realizado no início do } \\
\text { projeto alterações nos } \\
\text { mobiliários, correção e } \\
\text { orientação sobre postura. } \\
\text { Educação ergonômica: } \\
\text { passaram por sessões de } \\
\text { treinamento sobre } \\
\text { ergonomia. Controle: } \\
\text { somente receberam um } \\
\text { folheto informativo. }\end{array}$ & $\begin{array}{l}\text { educação ergonômica } \\
\text { apresentou menor desconforto } \\
\text { que o controle apesar de não } \\
\text { apresentar diferença } \\
\text { significativa. } \\
\text { - O grupo ergonomia intensiva } \\
\text { apresentou menor tensão } \\
\text { musculoesquelética nos } \\
\text { primeiros } 30 \text { dias do que os dois } \\
\text { respectivos grupos. }\end{array}$ & \\
\hline $\begin{array}{l}\text { Santos } \\
\text { et al. }\end{array}$ & $\begin{array}{l}\text { - Verificar os } \\
\text { benefícios da } \\
\text { ginástica } \\
\text { laboral na } \\
\text { prevenção da } \\
\text { DORT }\end{array}$ & $\begin{array}{l}\text { - Amostra: } 40 \\
\text { funcionárias do setor de } \\
\text { serviços gerais, divididas } \\
\text { em } 2 \text { grupos iguais, nos } \\
\text { quais realizavam ginástica } \\
\text { laboral } 2 \text { vezes na } \\
\text { semana (48 sessões). } \\
\text { - Foi realizado um } \\
\text { programa de ginástica } \\
\text { laboral do tipo } \\
\text { compensatório, formado } \\
\text { por: } 5 \text { min de } \\
\text { aquecimento, } 20 \text { min de } \\
\text { alongamentos e } 5 \text { min de } \\
\text { relaxamento. } \\
\text { - Também foram } \\
\text { realizadas palestras. } \\
\text { - Para avaliação antes e } \\
\text { após o programa, } \\
\text { utilizou-se de um } \\
\text { questionário modificado } \\
\text { e adaptado pelos autores, } \\
\text { composto por questões }\end{array}$ & $\begin{array}{l}\text { - Todas as funcionárias não } \\
\text { realizam revezamento, } \\
\text { permanecendo na mesma } \\
\text { atividade, faziam movimentos } \\
\text { repetitivos com os membros } \\
\text { superiores, além de trabalhar a } \\
\text { maior parte do tempo em pé. } \\
\text { - } 80 \% \text { da amostra relatou sentir } \\
\text { dor em alguma região do corpo } \\
\text { (maioria na coluna lombar e } \\
\text { ombro). Após o programa, } 75 \% \\
\text { melhoraram da dor. }\end{array}$ & $\begin{array}{l}\text { - Após o programa de } \\
\text { ginástica laboral, ocorreu } \\
\text { uma redução considerável } \\
\text { da dor das funcionárias e } \\
\text { melhora da qualidade de } \\
\text { vida, em relação às } \\
\text { condições de trabalho, } \\
\text { estado de humor, } \\
\text { motivação e disposição, o } \\
\text { que atua positivamente } \\
\text { nas prevenções de DORT. } \\
\text { - Pode-se considerar a } \\
\text { ginástica laboral uma } \\
\text { prática importante como } \\
\text { medida preventiva e } \\
\text { terapêutica, contribuindo } \\
\text { na redução da DORT. }\end{array}$ \\
\hline
\end{tabular}




\begin{tabular}{|c|c|c|c|c|}
\hline & & $\begin{array}{l}\text { referentes às condições } \\
\text { organizacionais, } \\
\text { sintomatológicas e nível } \\
\text { de satisfação das } \\
\text { funcionárias. } \\
\text { - Também foi analisado o } \\
\text { tempo de trabalho, pausa } \\
\text { para descanso, } \\
\text { revezamento de tarefas, } \\
\text { relacionamento } \\
\text { interpessoal. }\end{array}$ & & \\
\hline $\begin{array}{l}\text { Martins e } \\
\text { Barreto }^{13}\end{array}$ & $\begin{array}{l}\text { - } \\
\text { Verificar/identi } \\
\text { ficar resultados } \\
\text { em } \\
\text { funcionários } \\
\text { do Instituto de } \\
\text { Física da } \\
\text { Universidad } \\
\text { e de São } \\
\text { Paulo, } \\
\text { Campus São } \\
\text { Carlos, que } \\
\text { vivenciaram } \\
\text { da ginástica } \\
\text { laboral no } \\
\text { ano de } 2002 \\
\text { a } 2005 .\end{array}$ & $\begin{array}{l}\text { - Amostra: } 13 \\
\text { funcionários do setor } \\
\text { administrativo. Todos } \\
\text { executavam suas funções } \\
\text { na posição sentada, com } \\
\text { uso do computador, } \\
\text { mesa, cadeira e telefone, } \\
\text { com jornada de trabalho } \\
\text { de } 8 \text { horas diárias. } \\
\text { - O programa foi iniciado } \\
\text { em } 2002 \text {, sendo } \\
\text { realizado: } 2 \text { sessões por } \\
\text { semana com exercícios } \\
\text { estáticos, por } 20 \text { min, no } \\
\text { final do expediente. } \\
\text { - Em } 2003 \text { o programa era } \\
\text { realizado de manhã e a } \\
\text { tarde. Já em } 2004, \text { foram } \\
\text { realizadas } 4 \text { sessões } \\
\text { semanais no período da } \\
\text { manhã. } \\
\text { - Foram aplicados } \\
\text { questionários, com } \\
\text { questões abertas e } \\
\text { fechadas relacionadas ao } \\
\text { tempo de trabalho diário, } \\
\text { instrumentos de trabalho } \\
\text { utilizado, tipo e } \\
\text { frequências de } \\
\text { comportamento durante } \\
\text { a rotina do trabalho, se } \\
\text { permanecem muito } \\
\text { tempo sentado ou em pé. } \\
\text { Foram aplicados os } \\
\text { seguintes testes: o teste } \\
\text { do banco de Wells e } \\
\text { flexiteste. }\end{array}$ & $\begin{array}{l}\text { - No inicio (2002) a maioria dos } \\
\text { funcionários relataram dores na } \\
\text { coluna ao acordar, em } 2005 \text { os } \\
\text { percentuais foram diminuídos } \\
\text { significativamente. } \\
\text { - A progressão do alivio das } \\
\text { dores de } 2002 \text { a } 2005 \text { foi de } \\
85 \% \text { á } 100 \% \text {. }\end{array}$ & $\begin{array}{l}\text { - Na análise da percepção } \\
\text { de esforço notou-se } \\
\text { melhora no alívio das } \\
\text { dores durante o trabalho e } \\
\text { ao acordar. } \\
\text { - A aplicação do programa } \\
\text { de ginástica laboral para } \\
\text { os funcionários gerou } \\
\text { resultados positivos. } \\
\text { - Também foi relatado } \\
\text { verbalmente uma } \\
\text { diferença perceptível } \\
\text { quando as sessões foram } \\
\text { realizadas } 4 \text { vezes por } \\
\text { semana. }\end{array}$ \\
\hline $\begin{array}{l}\text { Carvalho } \\
\text { et al. }{ }^{14}\end{array}$ & $\begin{array}{l}\text { - Avaliar a } \\
\text { presença de } \\
\text { distúrbios } \\
\text { osteomuscular } \\
\text { es } \\
\text { relacionados } \\
\text { ao trabalho }\end{array}$ & $\begin{array}{l}\text { - Amostra: alunos do } \\
\text { quinto e nono semestres } \\
\text { que estavam } \\
\text { desenvolvendo atividades } \\
\text { clínicas em faculdades de } \\
\text { Odontologia de Recife e } \\
\text { Pernambuco. }\end{array}$ & $\begin{array}{l}\text { - Participaram } 227 \text { alunos. } \\
\text { - } 42 \text { alunos relataram que já } \\
\text { tinham sido diagnosticados com } \\
\text { DORT, como bursite, tendinite e } \\
\text { dorsalgia. } \\
\text { - } 173 \text { relataram dor ou fadiga } \\
\text { durante ou após os }\end{array}$ & $\begin{array}{l}\text { - Foi encontrado um risco } \\
\text { aumentado de } \\
\text { desenvolvimento de } \\
\text { lesões } \\
\text { musculoesqueléticas e } \\
\text { condições de dor } \\
\text { persistente. }\end{array}$ \\
\hline
\end{tabular}




\begin{tabular}{|c|c|c|c|c|}
\hline & $\begin{array}{l}\text { (DORT) em } \\
\text { estudantes de } \\
\text { odontologia } \\
\text { em duas } \\
\text { faculdades } \\
\text { brasileiras. }\end{array}$ & $\begin{array}{l}\text { - Foi aplicado um } \\
\text { questionário de auto } \\
\text { relato com } 20 \text { questões. } \\
\text { - A validade do } \\
\text { questionário foi testada } \\
\text { em um estudo piloto. }\end{array}$ & $\begin{array}{l}\text { atendimentos aos pacientes e } \\
\text { foi verificada diferença } \\
\text { significativa entre os sexos, com } \\
\text { ocorrência de dor foi maior } \\
\text { entre as mulheres. } \\
\text { - } 146 \text { indivíduos relataram } \\
\text { tomar medidas preventivas } \\
\text { contra a DORT, pela utilização } \\
\text { do mobiliário adequado, pausa } \\
\text { durante o trabalho e técnicas } \\
\text { de relaxamento muscular. }\end{array}$ & \\
\hline $\begin{array}{l}\text { Ferreira } \\
\text { et al. }{ }^{15}\end{array}$ & $\begin{array}{l}\text { - Analisar a } \\
\text { ergonomia de } \\
\text { um setor } \\
\text { financeiro e as } \\
\text { posturas dos } \\
\text { funcionários } \\
\text { durante as } \\
\text { tarefas e } \\
\text { propor } \\
\text { soluções para } \\
\text { minimizar } \\
\text { riscos } \\
\text { ergonômicos. }\end{array}$ & $\begin{array}{l}\text { - Amostra: } 10 \\
\text { funcionários de uma } \\
\text { assistência técnica } \\
\text { financeira (ATF), que } \\
\text { utilizavam o computador. } \\
\text { - Os métodos para } \\
\text { avaliação foram: } \\
\text { aplicação do questionário } \\
\text { SF-36 (avalia a qualidade } \\
\text { de vida relacionada à } \\
\text { saúde), a RULA (rapid } \\
\text { upper limb assessment) } \\
\text { (composta por diagramas } \\
\text { de posturas corporais e } \\
\text { avalia a exposição a } \\
\text { fatores de risco), o } \\
\text { Checklist de Couto } \\
\text { (determina o risco } \\
\text { ergonômico da atividade } \\
\text { exercida), a AEFA (análise } \\
\text { ergonômica focada na } \\
\text { atividade), que guia a } \\
\text { observação do posto de } \\
\text { trabalho e da atividade } \\
\text { de uso do computador. } \\
\text { - Os resultados obtidos } \\
\text { foram analisados para } \\
\text { avaliar os impactos na } \\
\text { qualidade de vida dos } \\
\text { trabalhadores e permitir } \\
\text { sugerir intervenções } \\
\text { preventivas. }\end{array}$ & $\begin{array}{l}\text { - } 4 \text { funcionários indicaram } \\
\text { regiões de desconforto: no } \\
\text { pescoço, ombros, braço, coluna } \\
\text { e quadril. } \\
\text { - Na qualidade de vida (SF-36) } \\
\text { todos os indivíduos } \\
\text { apresentaram escores altos. } \\
\text { - Na avaliação pela RULA, 80\% } \\
\text { dos funcionários apresentaram } \\
\text { pontuações altas, o que indica a } \\
\text { necessidade de investigação } \\
\text { mais detalhada e mudanças } \\
\text { necessárias imediatas. } \\
\text { - Com o Checklist de Couto foi } \\
\text { encontrado a presença de risco } \\
\text { de DORT improvável, porém } \\
\text { possível. } \\
\text { - Na AEFA os resultados são os } \\
\text { mesmos para toda amostra. }\end{array}$ & $\begin{array}{l}\text { - O ambiente de trabalho } \\
\text { apresentava } \\
\text { características } \\
\text { ergonômicas adequadas } \\
\text { para a atividade de uso do } \\
\text { computador, mas havia o } \\
\text { uso incorreto dos } \\
\text { equipamentos, posturas } \\
\text { inadequadas e má } \\
\text { distribuição de tarefas, } \\
\text { sendo possível ocorrência } \\
\text { de DORT. }\end{array}$ \\
\hline
\end{tabular}

\section{DISCUSSÃO}

Nesta revisão bibliográfica foi possível verificar que os estudos selecionados utilizaram principalmente questionários (sobre dor, estresse, tempo de trabalho, pausa e o tipo da tarefa) para avaliar o trabalhador. Também foi observado diversos relatos de queixas de dor pelos trabalhadores em diversas regiões do corpo e estes apontam a possível relação com o trabalho realizado de forma contínua, na mesma posição e com repetitividade. Foram feitas análises e modificações ergonômicas do ambiente de trabalho, orientações posturais e de atividade física, além da realização de ginástica laboral, na qual foi demonstrado que com a realização desta, verificou-se a melhora da qualidade de vida dos trabalhadores.

No estudo de De Marco et al. ${ }^{16}$, foi utilizado questionários para análise do local de trabalho, sobrecarga, sintomas psiquiátricos 
(como estresse e depressão) e qualidade de vida, dado este que foi visualizado com os estudos apresentados nesta revisão.

Foram verificados relatos de dor nos estudos analisados, principalmente na região cervical, ombros e lombar, conforme já relatado. Fato que corrobora parcialmente com o estudo de Rumaquella e Santos Filho ${ }^{17}$, que relatam que as regiões de maiores desconfortos foram a lombar, a dorsal, as pernas, o pescoço, os ombros e a coxa. Já no estudo de Lima et al. ${ }^{18}$ também foi apresentado relato de dores musculoesqueléticas, nas mesmas regiões que as descritas nesta revisão.

Neves $^{19}$ enfatiza que a DORT pode ser decorrente da condição de trabalho e pode acometer ambos os sexos. Foi visualizado nesta revisão que a forma como é realizado o trabalho, - ambiente e a carga horária podem estar vinculados com comprometimentos, como a dor e desconforto verificados neste. Augusto et al. ${ }^{20}$, cita que a dor e a parestesia podem ser sinais subjetivos da possibilidade de início de DORT, o que demonstra a importância da visualização destes acometimentos precocemente para implantação preventiva.

No estudo de Silva et al. ${ }^{21}$, também foram analisados os mobiliários de uma empresa, com uso de questionários e fotos, no qual foi verificado que, a postura sentada por longos períodos, o alto nível de concentração e a presente inadequação ergonômica dos postos de trabalho desencadeou desconforto e dor. E os autores relatam que este fato apresenta influência maléfica sobre o nível de produtividade e qualidade de vida do funcionário.

Análises e intervenções ergonômicas foram realizadas no ambiente de trabalho em metade dos estudos pesquisados, além da realização de orientações e ginástica laboral. Acredita-se que a junção entre ambiente ergonomicamente adequado com a prática de intervenção fisioterapêutica (como a ginástica laboral e orientações), podem apresentar efeitos positivos $^{22}$.

Metade dos estudos utilizou de orientações (palestras e panfletos) sobre ergonomia e exercícios, de forma preventiva e curativa relacionada ao trabalho. Alexandre ${ }^{23}$ enfatizou em seu estudo que, um cuidadoso planejamento antes de iniciar e durante as atividades laborais na forma de orientações básicas com enfoque ergonômico é essencial.

A maioria dos estudos utilizados nesta pesquisa relatou que a ginástica laboral auxiliou de forma preventiva diretamente na possibilidade do surgimento de DORT, além de melhorar a qualidade de vida do trabalhador. $\mathrm{Na}$ pesquisa de Candotti et al. ${ }^{24}$, a ginástica laboral foi eficaz na diminuição da intensidade e frequência da dor, e na correção dos hábitos posturais inadequados durante o trabalho, o que melhorou a postura laboral e apresentou efeitos positivos sobre a dor nas costas de trabalhadores que realizavam atividades laborais por longos períodos na posição sentada.

Souza e Ziviane ${ }^{25}$ avaliaram em sua pesquisa a abordagem da ginástica laboral para melhoria das condições de trabalho. Verificou-se o aumento na produtividade, um ambiente mais saudável, além de enfatizar que com o uso de medidas preventivas (como fizeram uso da ginástica laboral), ocorreu melhora na qualidade de vida dos trabalhadores, fato também verificado neste estudo. Aspectos relacionados à redução de acidentes e doenças ocupacionais foram notados de forma significativa, devido à diminuição no percentual de estresse, melhora da relação entre os colegas de trabalho, melhor disposição para o trabalho, principalmente nas atividades que incluem movimentos repetitivos.

Nesta revisão não foram encontradas publicações que apresentassem resultados negativos de trabalhos que fizessem uso de medidas preventivas relacionadas à fisioterapia, como análise e orientação ergonômica ou ginástica laboral sobre a prevenção de doenças musculoesqueléticas relacionadas ao trabalho, fato que também foi relatado por lkari et al. ${ }^{26}$.

Como limitações deste estudo destacamse o número limitado de estudos analisados devido ao enfoque restrito da pesquisa. Mesmo com estas limitações, os resultados demonstraram o que está sendo realizado pelas pesquisas e a importância da prevenção para melhor qualidade de vida dos trabalhadores.

\section{CONCLUSÕES}

Os estudos apresentaram resultados positivos em relação a medidas preventivas a DORT, sendo utilizada a ginástica laboral, avaliação e intervenção ergonômica, palestras e panfletos informativos sobre postura e atividade 
física. Além, dos estudos relatarem a melhora da qualidade de vida dos trabalhadores, o que reflete no aumento da produtividade, fato que enfatiza a importância da aplicação de medidas fisioterapêuticas preventivas.

E devido aos altos índices de transtornos traumáticos cumulativos nos últimos anos, faz-se necessário a realização de estudos que informem sobre intervenções preventivas para amenizar ou resolver essa problemática.

\section{CONFLITO DE INTERESSE}

Os autores declaram não haver qualquer potencial conflito de interesse que possa interferir na imparcialidade deste trabalho científico.

\section{REFERÊNCIAS}

1. Filho LGC, Pereira AA. LER/DORT: multifatorialidade etiológica e modelos explicativos. Interface comum. Saúde Educ. 2004;8(14):149-62. DOI: https://doi.org/10.1590/S1414-32832004000100009

2. Brasil. Ministério da Saúde. Dor relacionada ao trabalho. Brasília, 2012. Acesso em: 25 nov. 2016. Disponível em: http://bvsms.saude.gov.br/bvs/publicacoes/dor relaci onada trabalho ler dort.pdf

3. Brasil. Ministério da Saúde. Protocolo de atenção integral à saúde do trabalhador - LER/DORT. Brasília, 2006.

4. Melo VF, Barros IM, Freitas NAB, Luzes R. Incidência de distúrbios osteomusculares relacionados ao trabalho (DORT), em trabalhadores do setor administrativo do Instituto Nacional de Metrologia, Qualidade e Tecnologia (Inmetro), Rio De Janeiro, Brasil. Rev Saúde Física Mental. 2013;2(1):22-9.

5. Blanco MC. O processo de terceirização nos bancos: terceirização - diversidade e negociação no mundo do trabalho. Núcleo de estudos sobre trabalho e sociedade, Centro Ecumênico de Documentação e Informação. São Paulo: Editora Hucitec; 1994.

6. Araújo MA, De Paula MVQ. LER/DORT: um grave problema de Saúde Pública que acomete os cirurgiõesdentistas. Revista APS. 2003;6(2):87-93.

7. Barbosa MAS, Santos RM, Trezza MCSF. A vida do trabalhador antes e após a lesão por esforço repetitivo (LER) e doença osteomuscular relacionada ao trabalho (DORT). Rev Bras Enferm. 2007;60(5):491-6. DOI: https://doi.org/10.1590/S0034-71672007000500002
8. Pereira EF, Teixeira CS, Santos A. Qualidade de Vida: abordagens, conceitos e avaliação. Rev Bras Educ Fis Esporte. 2012;26(2):241-50. DOI: https://doi.org/10.1590/S1807-55092012000200007

9. Renner JS. Ergonomia e Fisioterapia: Ferramentas para produção de saúde e otimização do trabalho. Novo Hamburgo: O Empresário; 2003.

10. Miyamoto ST, Salmosos C, Mehanna A, Batistela $A E$, Sato T, Grego ML. Fisioterapia preventiva atuando na ergonomia e no stress no trabalho. Rev Fisioter Univ São Paulo. 1999;6(1):83-91. DOI: http://dx.doi.org/10.1590/fpusp.v6i1.79596

11. Ketola R, Toivonen R, Häkkänen $M$, Luukkonen R, Takala EP, Viikari-Juntura E, Expert Group in Ergonomics. Effects of ergonomic intervention in work with video display units. Scand J Work Environ Health. 2002;28(1):18-24. DOI: https://doi.org/10.5271/sjweh.642

12. Santos AF, Oda JY, Nunes APM, Gonçalves L, Garnés FLS. Benefícios da Ginástica laboral na Prevenção dos Distúrbios Osteomusculares relacionados ao Trabalho. Arq Cienc Saúde Unipar. 2007;11(2):99-113. DOI: https://doi.org/10.25110/arqsaude.v11i2.2007.1520

13. Martins GC, Barreto SMG. Vivências de ginastica laboral e melhoria da qualidade da qualidade de vida do trabalhador: resultados apresentados por funcionários administrativos do instituto de física da Universidade de São Paulo (Campus São Carlos). Motriz. 2007;13(3):214-24.

14. Carvalho MV, Soriano EP, Caldas Jr AF, Campello RI, Miranda HF, Cavalcanti FI. Work-Related Musculoskeletal Disorders Among Brazilian Dental Students. J Dent Educ. 2009;73(5):624-30.

15. Ferreira VMV, Shimano SGN, Fonseca MCR. Fisioterapia na avaliação e prevenção de riscos ergonômicos em trabalhadores de um setor financeiro. Fisioter Pesq. 2009;16(3):239-45. DOI: http://dx.doi.org/10.1590/S1809-

$\underline{29502009000300009}$

16. De Marco PF, Citero VA, Moraes E, Martins LAN. O impacto do trabalho em saúde mental: transtornos psiquiátricos menores, qualidade de vida e satisfação profissional. J Bras Psiquiatr. 2008;57(3):178-83. DOI: https://doi.org/10.1590/S0047-20852008000300004

17. Rumaquella MR. Postura de trabalho relacionada com as dores na coluna vertebral em trabalhadores de uma indústria de alimentos: estudo de caso. 
[Dissertação]. Universidade Estadual Paulista, Bauru, 2009.

18. Lima VA, Aquilas AL, Junior MF. Efeitos de um programa de exercícios físicos no local de trabalho sobre a percepção de dor musculoesquelética em trabalhadores de escritório. Rev Bras Med Trab. 2009;7:11-7.

19. Neves IR. LER: trabalho, exclusão, dor, sofrimento e relação de gênero. Um estudo com trabalhadoras atendidas num serviço público de saúde. Cad Saúde Pública. 2006;22(6):1257-65. DOI: https://doi.org/10.1590/S0102-311X2006000600015

20. Augusto VG, Sampaio RF, Tirado MGA, Mancini MC, Parreira VF. Um olhar sobre as LER/DORT no contexto clínico do fisioterapeuta. Rev Bras Fisioter. 2008;12(1):49-56.

DOI: https://doi.org/10.1590/S1413-35552008000100010

21. Silva CR, Silva MAC, Silva SR, Souza JCC, Santos SD. Ergonomia: um estudo sobre sua influencia na produtividade. Rev Gestão USP. 2009;16(4):61-75. DOI: https://doi.org/10.5700/rege380

22. Bernaads CM, Ariens GA, Hildebrandt VH. The (coast) effectivnees of a lifestyle physical activity intervention in addition to a work style intervention on the recovery from neck and upper limb symptoms in computers workers. BMC Musculoskelet Disord. 2006;7:80. DOI: https://doi.org/10.1186/1471-2474$\underline{7-80}$

23. Alexandre NMC. Aspectos ergonômicos e postura e o trabalhador da área de saúde. Semina Ciên Biol Saúde. 2007;28(2):109-18. DOI: https://doi.org/10.5433/1679-0367.2007v28n2p109

24. Candotti CT, Stroschein R, Noll M. Efeitos da ginástica laboral na dor nas costas e nos hábitos posturais adotados no ambiente de trabalho. Rev Bras Ciên Esporte. 2011;33(3):699-714.

25. Sousa FKN, Ziviani F. A qualidade de vida no trabalho correlacionado á prática de Ginástica Laboral. Rev. Cient Dep Ciên Jurídicas Gerenciais do UNI-BH. 2010;3(1).

26. Ikari TE, Mantelli M, Corrêa Filho HR, Monteiro MI. Tratamento de ler/dort: intervenções fisioterápicas. Rev Ciênc Med. 2007;16(4-6):233-43.
Recebido para publicação em 22/07/2016

Revisado em 29/06/2017

Aceito em 10/05/2018 